\title{
The Impact of Covid-19 Pandemic on Africa's Healthcare System and Psychosocial Life
}

\author{
Amanze Nkemjika Ikwu \\ Cardiology Department, University Hospitals \\ Plymouth NHS Trust, United Kingdom \\ David Chinasa Igwe \\ Nottinghamshire Healthcare NHS Foundation \\ Trust, United Kingdom \\ Sixtus Ezenwa Nwawudu \\ Nottinghamshire Healthcare NHS Foundation \\ Trust, United Kingdom \\ Adeyemi Samuel Adebayo \\ Department of Crop Production and Protection, \\ Obafemi Awolowo University, Ile-Ife, Nigeria
}

\section{Abstract}

The ravaging Corona virus caused many countries of the world to impose partial or total lockdown, African nations inclusive. Most African countries are low-income countries, with most of the population being non-office workers. With the continued spread and rise of COVID-19 in many African nations, the people had no choice but to keep working for their daily survival. Moreover, the current health system in most African countries is weak and unable to tackle the emerging COVID-19 pandemic. The extra burden of the COVID-19 pandemic exposed these gaps and weaknesses. In addition to the effect of the pandemic on Africa's healthcare system, there is an equal and parallel debilitating effect of the virus on the psychosocial lives of Africans. Regardless of the several challenges that African nations face; Is there any way forward? African leaders may be able to unite and reduce their dependency on the international community for aids during health crises. They may also collectively take proactive decisions on strengthening their health systems as they work on educating their people.

Keywords: Corona virus, COVID-19, Africa, Healthcare, Psychosocial 


\section{Introduction}

The Ebola outbreak of 2014 exposed how bad the state of health systems in Africa was. The World Health Organization (WHO) declared it a public health emergency of international concern on August 8, 2014. Barely two months later, on November 14 of the same year, more than 14,400 people had contracted the disease in eight countries, including Liberia, Sierra Leone, Guinea, and Nigeria, with a case fatality rate (CFR) of $35.92 \% . \quad[\underline{1}, \underline{2}]$

In Nigeria, the index case of the Ebola crisis was a traveler from Liberia who collapsed at the Lagos airport; this made it easy for him and several contacts to be traced and the efficient curb. When Nigeria was announced devoid of the virus, 20 people had contracted it with up to 8 deaths, a CFR of $40 \%$. Five of these were health workers [3]]. With 2814 deaths of 6878 cases in Liberia (40.88\% CFR), 1166 deaths of 1919 cases in Guinea (60.76\% CFR) and 1187 deaths of 5586 cases in Sierra Leone $(21.45 \%$ CFR), the feedback from the international community on the Ebola epidemic outbreak response in West Africa was that it was unsurprisingly slow, disorganized and weak $[1, \underline{4}]$.

At the end of the Ebola crisis of 2014/2015, it was expected that Africa might concentrate more resources to the health sector and improve the overall health system. However, this was not the case. The health sectors in several African countries are still severely lacking with outdated technology and inadequate facilities, a sparse number of doctors available to treat an overwhelming amount of patients, low healthcare worker wages without insurance, and reoccurring strike action by healthcare workers in several parts of the continent. Wealthy citizens and politicians of African countries have resulted in traveling to European or American countries to get the best healthcare, neglecting to invest or contribute to the home continent's healthcare systems. Considering the current state of the health systems across Africa, the debilitating effect of the Corona virus and inability to contain it is unsurprising.

In April 2001, several leaders of the African Union had a meeting in Abuja, Nigeria. Following the meeting, African leaders promised to allocate at least $15 \%$ of each country's annual budget to the health sector [ $\underline{5}$ ]. Yet, according to United Nations Economic Commission for Africa (UNECA) 2019 report, Africa's global health expenditure is less than $2 \%$ while they have more than $36 \%$ of the worldwide health burden.

In a 2017 analysis by the World Bank, more developed countries spend more than $10 \%$ of the Gross Domestic Product (GDP) on health. The United States spent 17.6\% on health, Germany spent $11.25 \%$, France spent $11.31 \%$, and Switzerland spent $12.35 \%$. African countries, however, spent an average of $5 \%$ of their GDP on health. Nigeria in West Africa spent 3.76\%, South Africa spent 8.11\%, Kenya spent 4.80\%, and the Central Africa Republic spent 5.82\% (ㅁ). African countries are some of the most populated nations in the world. Nigeria is the most populated country in Africa, 
with an estimated population of $195,874,740$ people in 2016, followed by Ethiopia, with $109,224,559$ people and Egypt with 98,423,595 people [7].

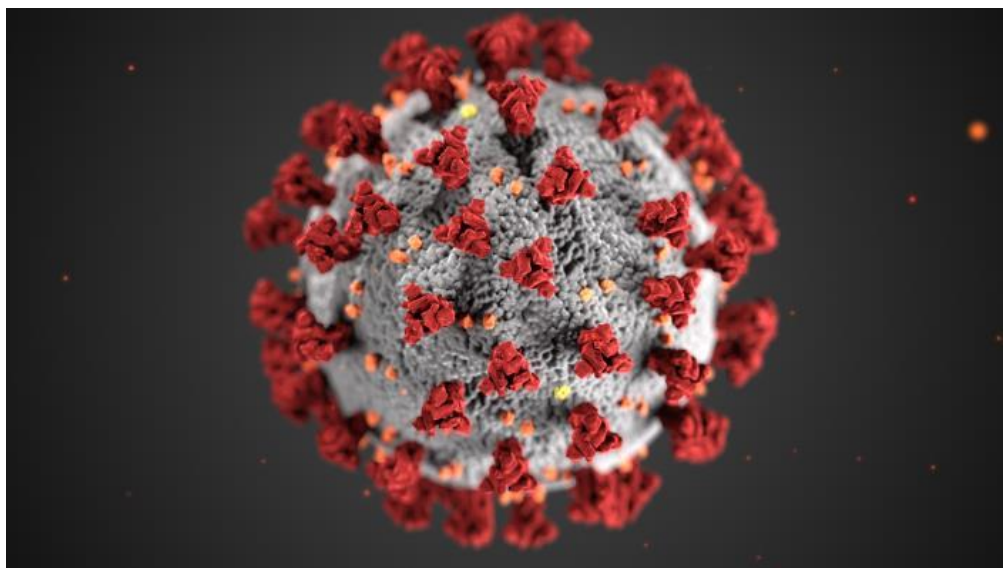

Picture 1: structural morphology exhibited by corona viruses

\section{Effect of the Corona Virus Pandemic on Africa's Healthcare System}

South Africa is one of the African countries diverting most of their GDP to healthcare, yet they have about 0.776 doctors to 1,000 people. Mozambique has about 0.07 doctors per 1000 people. In sub-Sahara Africa, there is an average of 0.19 doctors to 1,000 people, and Africa, as a whole, has approximately one doctor to every 5,000 people [ ]. Most African countries have less than one hospital bed per 1000 people. South Africa has 0.75 beds in intensive care unit (ICU) per million people, while Uganda has one bed in ICU per 1 million people. This is in contrast to 336 ICU beds per million people in the US [1; 9]. In 2013, sub-Saharan Africa had a deficit of 1.8 million doctors, and this is due to lack of funding, inadequate training, and education, international migration of health workers for several reasons and career change [10]. This was the known state of the continent before the COVID-19 virus outbreak.

In the most populated African country, Nigeria, strike action by health workers is a widespread phenomenon. It is not strange to hear about these industrial actions even during times of national health emergencies such as Ebola, Lassa Fever, or Cholera outbreaks. The most common cause of these actions in Nigeria is healthcare management and leadership issues. Demand for higher wages and infrastructural problems are also important reasons for strike actions in Nigeria and other African countries [11]. Another African country that is known for strike action is South Africa.

At a very pivotal period in the spread and maintenance of the COVID-19 virus in Nigeria, with more than 15,000 cases in June, the National Association of Resident Doctors of the country decided to embark on a strike action that lasted several days. Similarly, a significant challenge faced during the Ebola crisis of 2014 in Nigeria was the strike action during the period. Nigeria is better suited to remedial treatment rather than preventive treatments [12]. 
The transmission of the novel corona virus SARS-COV-2, which originated from China, started in Africa later than other countries for reasons speculated to be a warmer climate but most likely due to limited international air traffic in the continent [13]. There is, however, dense traffic, especially between China and African countries. WHO listed 13 top priority African countries including Algeria, Angola, Cote d'Ivoire, the Democratic Republic of the Congo, Ethiopia, Ghana, Kenya, Mauritius, Nigeria, South Africa, Tanzania, Uganda, Zambia. All of whom have direct traffic link with China and most of whom do not have sufficient or appropriate diagnostic capacity to handle the outbreak [14].

The first case in Africa was reported on February 14, 2020, in Cairo, Egypt. 13 days later, the first case in Nigeria was reported, an individual traveling from Italy. The most distinguishing factor of the Corona virus and pointer of its debilitating effect on Africa's health system is that Africa would have to rely on the preexisting health system to deal with the virus. The continent could not rely heavily on other continents for help as they had in previous African epidemics. This time, most countries of the world were preparing to tackle or already tackling the Corona virus with little success.

As of July 10, 2020, there are more than 550,000 cases of the Corona virus in Africa, with more than 270,000 active cases and 12,000 recoveries. South Africa has more than 250,000 cases followed by Egypt with 80,000 cases, Nigeria, with 31,000 cases, Ghana with 23,000 cases, and Algeria with 18,000 cases. On May 13, every African country had reported a case of the Corona virus $[15,16]$. The risk of death from COVID-19 increases with age, with more deaths in people over 60 years old [17]. This puts Africa more at risk as the continent is experiencing the fastest growing rate of older people than any other region in the world. There are more than 43 million people over 65 years old in sub-Saharan Africa alone. The percentage of people over 65 in Africa had increased from 3.3\% in 2000 to 3.6\% in 2010. Also, as of 2015, there was a larger population of older men (52\%) and older females (33\%) that are an active part of the labor force compared to the $30 \%$ and $15 \%$ average in the world older male and female workforce respectively $[\underline{18}, \underline{19}]$. The increasing number of cases of the virus in Africa may only serve to decimate an already overwhelmed and struggling health system in Africa.

Considering the current state of health systems in Africa, the continent can not afford to lose health workers to the pandemic. However, the most direct impact of the virus on the health system is seen on the health workers themselves. As of June 9, more than 2000 South African health workers have contracted the disease and more than 800 Nigerian healthcare workers, about $6 \%$ of the total cases. However, these are not the highest percentages of healthcare workers that have contracted

it on the continent. $19 \%$ of the total cases in Niger are healthcare workers, $12 \%$ of all cases in Sierra Leone and Liberia are healthcare workers, $10 \%$ of the cases in Namibia, and $9 \%$ of all cases in Zambia are all healthcare workers [20]. By June 29, 2020, the infected health workers in South Africa had increased to more than 3500, with 34 
deaths. It is not known yet, how many more healthcare workers will be affected or die from the virus, but the number is expected to increase in the coming months as there is a shortage of protective gear among healthcare workers in the continent.

Another effect of the virus on the health system is the incapacitation of hospitals, making them unable to provide adequate care to individuals with other health issues. With most hospitals, government-owned and private, filled with Corona virus patients, hospitals are too full to admit or attend to other patients. Doctors are also careful not to clerk patients at the risk of contracting the virus. Most patients have, therefore, resorted to self-care and medication at home. This may worsen the state of health of people. Hospitals may be filled with patients suffering from severe and worsened health issues long after curbing the virus and its spread.

\section{The Psychosocial Effect of the Corona Virus in Africa}

In an attempt to curb the spread of the virus, several nations of the world quickly imposed total or partial lockdown in their cities and states. The lockdown has caused severe mental and psychosocial impacts on people in the world, such as mass hysteria, financial losses, depression, and anxiety. As the world locked out and advised people to work from home, if possible, most Africans faced anxiety as their businesses were locked up, and they descended into financial losses. How to take care of their families became a significant source of worry. Most people in Africa earn a living by practicing subsistence agriculture, selling in market stalls, or work as street vendors. People in low-income countries are six times more street vendors than people in high-income countries, and 17 times more agricultural laborers. In North America, 30\% of people have jobs that allow them to work from home. This is in contrast to the meager $6 \%$ of Africans who can afford to work from home. Even so, most African cities do not have efficient social and information technology infrastructure, which allows remote working to be productive [21]. Again, there is the problem of insufficient electricity and slow internet to deal with.

Developed countries provided palliatives for their citizens to get through the lockdown period, but most Africans were thrown into starvation as the several governments could not afford palliative measures. The economic crisis arising from the COVID-19 related global lockdown could possibly increase the suicidal risk and attempts in affected individuals [22]. In addition, discrimination and social boycott of infected patients may worsen their mental health issues and suicidal risk. This is more evident in African countries where economic and palliative support was lacking.

COVID-19 lockdown affected virtually every aspect of the life of people in Africa. Schools were closed just as well as businesses, and therefore, students had to return to their homes and families. Social activities were also suspended; thus, bars and beer parlors, as well as soccer viewing centers, were closed. Family or street landlord or elders' meetings were suspended, religious activities were also suspended, and the closing of churches or mosques ensued. Wedding parties or gathering with more than 20 people were also banned in most cities. Thus, stay-at-home orders can create 
sudden changes to people's social life [23], especially for Nigerians who are known to have a rich sociocultural heritage of partying and hanging out (24). They are keen on maximally utilizing any social activity and networking opportunity. Thus, a negative psychological effect on the Nigerian population is expected following the lockdown, social distancing and mandatory use of face masks (24). With the COVID-19 pandemic in Nigeria, there is a significant prevalence in psychological distress: $15 \%$ for insomnia, 23\% for depression and 25\% for severe post-traumatic stress [24]. Olaseni, et al (2020) suggested that multiple misleading COVID-19 information from social media and the rise in confirmed cases in Nigeria could have aggravated the experience of post-traumatic stress symptoms among Nigerians [24]. Their study showed that there was no significant difference between male and female psychological distress experienced by Nigerians during the COVID-19 pandemic.

One of the basic defense mechanisms for survival adapted by animals is fear. However, when fear becomes long-standing and out of proportion it can lead to mental health issues [25]. The number of individuals affected mentally by COVID-19 is greater than those who are actually infected especially in most African countries where the infection rate is low. Another study reported a significant increase in fear and apprehension among both health workers and the entire population due to the high fatality of COVID-19, lack of preventive and protective equipment, massive misinformation/information being circulated, the negative effects caused by the lockdown and unfamiliar restrictions that infringe on personal freedom. They concluded that COVID-19 related isolation and stigma for COVID-19 are potential causes of mental health disorders like anxiety, obsessive compulsive disorder (OCD), depression, post-traumatic stress disorder (PTSD), adjustment disorders and sleep disorders [26].

Furthermore, there has been a significant rise of anxiety, stress and burn-out among healthcare professionals. A significant proportion of healthcare workers are either shielding or sick at home. Thus, the remaining workers on duty have to work under pressure with a relatively higher workload than usual. In addition, forefront healthcare workers are in constant fear of getting infected and are also psychologically distressed and traumatised by experiencing the death of infected patients [22]. There are also cases of increased malingering by front-line healthcare workers; about $25 \%$ of them hardly come to work. Most of them avoid work by giving frenzy reasons while some feign illness [26].

Nkporbu et. al, 2020 reported that common responses from people include worrying about the likelihood that their family members are infected, the fear of getting ill and dying, losing their loved ones, helplessness as they are unable to protect loved ones, stress relating to separation arising from being quarantined, boycotting health facilities due to fear of getting infected while in care and anxiety of not being able to work during isolation. In addition, uncertain prognoses, limited resources for testing 
and treatment facilities, and conflicting messages from authorities are also significant factors that contributed to increased COVID-19 related mental health issues (26).

Coupled with financial loss, families, and parents felt incompetent to care for their families. This is coupled with the burnout, panic, and anxiety that most people feel from fear of contracting the disease. The impact of the virus led to increased substance abuse and overall mental distress (27). The infection and measures that followed may cause new mental illnesses due to increased depression, anxiety, and substance abuse in people. It may also cause an increase in preexisting mental conditions [28].

Another impact of the virus on people is the increase of domestic and gender-based violence in Africa. Partners had to stay home during the lockdown, some of them with abusive partners. Children that moved back home from school, staying in their homes, also faced physical and mental abuse from parents or guardians. Though social isolation is effective in controlling infections, it can cause significant socioeconomic, emotional and psychological consequences which can in turn trigger family violence, especially in the background of increased use of negative coping mechanisms such as alcohol [29]. Furthermore, during isolation, there are limited opportunities to call for help by individuals living with family abuse. It should be noted that isolation helps the abused victims to keep physical and emotional signs of abuse less visible from the public. Thus, help and support from third parties are highly limited.

In the months of May and June, 2020, there was a major outrage on social media regarding the increased number of domestic abuse and rape cases in Nigeria. In March, Lagos state government of Nigeria reported 380 cases of sexual and domestic violence; this is a $60 \%$ increase in domestic violence, a $30 \%$ increase in sexual abuse, and a $10 \%$ increase in child abuse (30). South Africa, however, reported a significant drop by 69.4\% from March-April 2019 and the lockdown in 2020. There have been speculations that this may be due to the ban on sales of alcohol. But this drop in sexual and domestic violence may be as a result of the total lockdown, in which victims are locked in with their abusers and too afraid to go out to report or make phone calls to relevant authorities.

With regards quarantined individuals, a study in Enugu, Nigeria proposed that in quarantined individuals, significant knowledge about COVID-19 was lower among those with psychological distress than among those without psychological distress. They suggested that it is essential to constantly educate people before, during and after quarantine [31].

On the other hand, though reduced social contact may initially result in loneliness and social isolation, recent studies suggest that a likely positive effect of COVID-19 pandemic is an increase in seeking social support or connectedness by individuals which may reduce loneliness in the long-term. Thus, long-term prospective studies are required to evaluate the course of psychological symptoms as the pandemic continues [23]. In Africa, stay-at-home orders provided an avenue for families to 
spend time together. Social support was mostly from nearby family members and friends, and most importantly palliatives from family members and kinsmen living abroad. However, remote social support through tele-services are lacking and even when available are inaccessible.

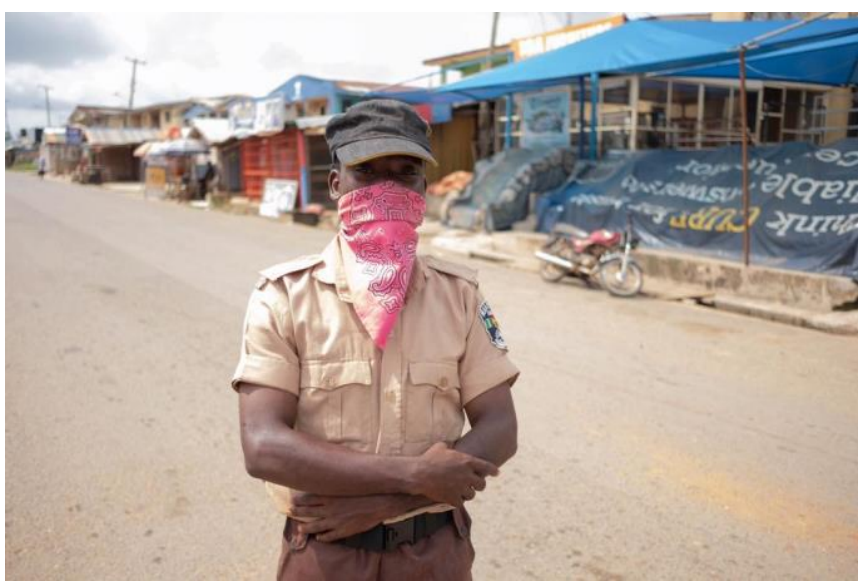

Picture 2: Ile-Ife town, Nigeria, during COVID-19 lockdown, May 2020.

\section{The Way Forward}

To prepare for future health emergencies, pandemics or epidemics, African governments have to review their health budgets, and GDP diverted to grow the health systems. African countries and governments should keep their 2001 promises and commitment during the Abuja declaration and meet the target $15 \%$ budget allocations to the health sector. With an increase in health budgets, appropriately allocated, and without corruption, the health facilities may be better geared. Doctors may also be encouraged to discontinue the culture of strike actions and serve their countries rather than look to migrate to countries where they can practice better and be appreciated more. There should also be more regular meetings between African leaders and health specialists on how to improve the health care systems of African countries as well as create a task force and execution team to uphold and implement the decisions made. The lessons learned from the current pandemic, as well as previous epidemics and health crises in Africa, should prepare Africa for the future and govern our decisions regarding health crisis management, even without the contributions or input of the international community.

It is also essential to set up post-COVID-19 mental health care centers to mitigate the debilitating psychological effects of the Corona virus and the strict measures taken on citizens. Several helplines such as suicide hotline, anxiety, and depression hotline should also be set up so that people get the support they need. Education of the masses should be planned so that people understand the psychological effects of COVID-19 and how best to handle the situation. Strict measures may also be put in place to discourage the spread of fake news on social media and television, as these 
media outlets need to be used appropriately to encourage and educate people rather than spread panic and fear. African nations should dedicate substantial portion of funds to cushion the hardship suffered by their citizens particularly the vulnerable ones. It is imperative for countries to review their restrictions as the pandemic evolves. It is also important to support healthcare workers, monitor their stress as well as cater for their welfare. Children and adolescents who have suffered the death of a loved one or friend and issues related to parental unemployment or loss of household income should be supported by state and federal governments. Again, it is equally advisable to monitor young people's mental health status over the long term, and to study how prolonged school closures, strict social distancing measures, and how COVID-19 pandemic itself affect their well-being. The provision of communitydriven mental health support by trained mental health community nurses and volunteers will go a long way in educating people and mitigate the psychological burden of COVID-19.

\section{References}

[1] World health organization (2016), Ebola Situation Report - March 2, 2016. https://apps.who.int/ebola/current-situation/ebola-situation-report-2march-2016

[2] Oleribe, O. O., Salako, B. L., Ka, M. M., Akpalu, A., McConnochie, M., Foster, M., \& Taylor-Robinson, S. D. (2015). "Ebola virus disease epidemic in West Africa: lessons learned and issues arising from West African countries." Clinical medicine (London, England), 2015 Feb; 15(1): 54-57. PMCID: PMC4954525, PMID: 25650199. https://www.ncbi.nlm.nih.gov/pmc/articles/PMC4954525/

[3] Althaus C.L., Low N, Musa E.O., Shuaib F, Gsteiger S. (2015) "Ebola Virus Disease Outbreak in Nigeria: Transmission Dynamics and rapid control." Epidemics Volume 11, June 2015, pp 80-84. https://www.sciencedirect.com/science/article/pii/S1755436515000341

[4] National Academies of Sciences, Engineering, and Medicine; Health and Medicine Division; Board on Global Health; Forum on Microbial Threats. The Ebola Epidemic in West Africa: Proceedings of a Workshop. Washington (D.C.): National Academies Press (U.S.); 2016 November 30. 2. The Outbreak. https://journals.plos.org/plosntds/article/file?type=supplementary\&id=in fo:doi/10.1371/journal.pntd.0006313.s001

[5] World health organization (2011), The Abuja declaration: Ten years on, accessed July 10 , 2020, https://www.who.int/healthsystems/publications/abuja_report_aug _2011.pdf?ua=1 
[6] The World Bank (2017), Current health expenditure (\% of GDP) - SubSaharan Africa, World. Accessed July 10, 2020, https://data.worldbank.org/indicator/SH.XPD.CHEX.GD.ZS?locations =ZG-1W\&most_recent_value_desc=false

[7] Andrew Mwaniki (2018), The 10 Most Populated Countries in Africa, Accessed July 10, 2020, https://www.worldatlas.com/articles/the10-most-populated-countries-in-africa.html

[8] Abairdqz (2015), Africa has about one doctor for every 5000 people, Accessed July 10, 2020, https://qz.com/520230/africa-has-about-one-doctor-forevery-5000-people/

[9] Wallace, D. J., Angus, D. C., Seymour, C. W., Barnato, A. E., \& Kahn, J. M. (2015). "Critical care bed growth in the United States. A comparison of regional and national trends". American journal of respiratory and critical care medicine, 191(4), 410-416.

https://europepmc.org/article/med/25522054\#free-full-text

[10] World health organization (2013), Web Annex 4: Workforce data for 193 countries, Accessed July 10, 2020, https://www.who.int/workforcealliance/knowledge/resources/We b_annex_4_WHO_Workforce_Statistics_f.pdf?ua $=1$

[11] Oleribe, 0.0., Ezieme, I.P., Oladipo, O. et al. (2016). Industrial action by healthcare workers in Nigeria in 2013-2015: an inquiry into causes, consequences and control-a cross-sectional descriptive study. Hum Resour Health 14, 46 (2016). https://pubmed.ncbi.nlm.nih.gov/27465121/

[12] Otu A., Ameh S., Osifo-Dawodu E., Alade E., Ekuri S., \& Idris J. (2017). An account of the Ebola virus disease outbreak in Nigeria: implications and lessons learnt. BMC public health, 18(1), 3.

https://www.springermedizin.de/an-account-of-the-ebola-virus-diseaseoutbreak-in-nigeria-implic/13292340

[13] Melisa Martinez-Alvarez, Alexander Jarde, Effua Usuf, Helen Brotherton, Mustapha Bittaye, Ahmadou L Samateh et al. (2020), COVID-19 pandemic in West Africa.The Lancet Global Health, Volume 8, Issue 5, e631 - e632, May 1, 2020. https://www.ncbi.nlm.nih.gov/pmc/articles/PMC7186549/

[14] Velavan, T. P., \& Meyer, C. G. (2020). The COVID-19 epidemic. Tropical medicine \& international health : TM \& IH, 25(3), 278-280. https://www.ncbi.nlm.nih.gov/pmc/articles/PMC7169770/

[15] John Hopkins University (2020), coronavirus resource centre, Accessed July 11, 2020, https://coronavirus.jhu.edu/map.html 
[16] Africa CDC (2020), coronavirus disease,2019, (COVID-19). Accessed July 11, 2020. https://africacdc.org/covid-19/

[17] Peter Lloyd-Sherlock, Shah Ebrahim, honorary, Leon Geffen, Martin McKee (2020). "Bearing the brunt of COVID-19: older people in low and middle-income countries". https://www.sigg.it/wpcontent/uploads/2020/03/covid-19-older-people-in-low-and-middleincome-countries.pdf

[18] Yumiko Kamiya 2016, DESA, Population Division United Nations Regional Workshop Lilongwe; overview of democratic ageing in Africa. United Nations. https://www.un.org/en/development/desa/population/events/o ther/15/index.asp

[19] Relief web, 2011. Ageing population challenges in Africa. Accessed July 11, 2020, https://reliefweb.int/report/world/aging-population-challengesafrica

[20] Peter Mwai and Christopher Giles (2020), Coronavirus: How vulnerable are health workers in Nigeria? https://www.bbc.com/news/world-africa53013413

[21] Janine Berg, Florence Bonnet, Sergei Soares (2020), Working from home: Estimating the worldwide potential. https://voxeu.org/article/workinghome-estimating-worldwide-potential,

[22] Thakur, V., \& Jain, A. (2020). COVID 2019-suicides: A global psychological pandemic. Brain, behavior, and immunity, 88, 952-953. Advance online publication. https://doi.org/10.1016/j.bbi.2020.04.062

[23] Matthew T. Tull, Keith A. Edmonds, Kayla M. Scamaldo, Julia R. Richmond, Jason P. Rose, Kim L. Gratz, Psychological Outcomes Associated with Stay-atHome Orders and the Perceived Impact of COVID-19 on Daily Life. https://www.ncbi.nlm.nih.gov/pmc/articles/PMC7252159/

[24] Olaseni, Abayomi O. and Akinsola, Olusola S. and Agberotimi, Samson Femi and Oguntayo, Rotimi, Psychological Distress Experiences of Nigerians Amid COVID-19. http://dx.doi.org/10.2139/ssrn.3596106

[25] Ornell, Felipe, Schuch, Jaqueline B., Sordi, Anne O., \& Kessler, Felix Henrique Paim. (2020). "Pandemic fear" and COVID-19: mental health burden and strategies. Brazilian Journal of Psychiatry, 42 (3), 232-235. Epub April 03, 2020. https://doi.org/10.1590/1516-4446-2020-0008

[26] Nkporbu A K et al., "Psychosocial Implications of the Coronavirus Pandemic: Early Study and Projections from Port Harcourt Nigeria", International Journal of Research Studies in Medical and Health Sciences. 2020; 5(4): 31-39. http://www.ijrsmhs.com/pdf/v5-i4/9.pdf 
[27] Dubey, S., Biswas, P., Ghosh, R., Chatterjee, S., Dubey, M. J., Chatterjee, S., Lahiri, D., \& Lavie, C. J. (2020). Psychosocial impact of COVID-19. Diabetes \& metabolic syndrome, 14(5), 779-788. Advance online publication. https://www.mobt3ath.com/uplode/book/book-94942.pdf

[28] Jose Luis Turabian (2020), Implications on mental health by the coronavirus disease 2019 (COVID-19) pandemic: The role of general practitioner. https://www.heighpubs.org/hjcap/apmh-aid1016.php

[29] Usher, K., Bhullar, N., Durkin, J., Gyamfi, N., \& Jackson, D. (2020). Family violence and COVID- $\quad$ 19: Increased vulnerability and reduced options for support. International journal of mental health nursing, 29(4), 549-552. https://doi.org/10.1111/inm.12735

[30] EJIRO UMUKORO (2020), Amidst COVID-19 Lockdown, Nigeria Sees Increased Sexual and Gender Violence. Accessed July 11, 2020, https://pulitzercenter.org/reporting/amidst-covid-19-lockdownnigeria-sees-increased-sexual-and-gender-violence

[31] Okoro J, Odionye T, Nweze B et al. COVID-19 pandemic, psychological response to quarantine, and knowledge of the disease among inmates in a Nigerian custodial center [version 2; peer review: 1 approved, 1 approved with reservations]. Emerald Open Res 2020, 2:26 (https://doi.org/10.35241/emeraldopenres.13684.2) 